\title{
Aprendiendo a entender. Victoria Ocampo y su descubrimiento de los Estados Unidos ${ }^{1}$
}

Mariano Plotkin

IDES/CONICET, Argentina

El artículo analiza la evolución de la compleja relación que la intelectual y empresaria cultural argentina Victoria Ocampo estableció con los Estados Unidos. A través de esta trayectoria, el artículo analiza también temas mas amplios como la evolución de los proyectos modernizadores de la élite social e intelectual argentina. Ocampo era a la vez. una representante típica y única de su clase social. Era típica por la manera en que fue educada en un ambiente cosmopolita. Era única por el lugar central que ocupó en el campo intelectual argentino desde la década de 1920 hasta su muerte a finales de los años 70.

Palabras Clave: Victoria Ocampo, Sur, Estados Unidos, élites intelectuales.

The article analyzes the evolving relationship that Argentine intellectual and cultural entrepreneur Victoria Ocampo established with the United States. Through her trajectory the article analyzes broader topics such as the evolution of the Argentine social and intellectual élite's project of modernization. Ocampo was at the same time a typical and a unique representative of the Argentine social élite. She was typical in the way she was educated in a cosmopolitan environment. She was unique because she occupied a central figure in the Argentine field of cultural production since the 1920 until her death in the late 1970s.

KEYwORDS: United States, intellectual elites.

En 1931 Victoria Ocampo, asistida por un grupo de jóvenes y brillantes intelectuales argentinos e inspirada por el ensayista estadounidense Waldo Frank, creó la revista Sur que se constituiría en un referente central en el mundo de las letras argentinas y latinoamericanas. Hasta al menos la década de 1960 Sur definió un área importante del gusto literario en el país y conformó un espacio de legitimación para escritores. Cuando un autor lograba que sus trabajos se publicaran en Sur se asumía que había "llegado." Sur surgió y se desarrolló como un componente central de la densa red de contactos internacionales que Ocampo se había encargado de tejer a su alrededor desde su juventud. Aunque el propósito original explicitado por

1 Versiones anteriores de este trabajo fueron presentados en inglés en el encuentro "Norte Americanization of Latin America?" Katolische Universitat, Eichstatt, Alemania, Julio 5-7, 2001, y en español en el coloquio "Los intelectuales en América Latina: continuidades y rupturas", Congreso de Latinoamericanistas españoles, Madrid, España, noviembre 2001. Deseo expresar mi gratitud a Stefan Rinke, Paula Siganevich, Lila Caimari, Rosana Guber, Piroska Csúri y Federico Neiburg por sus comentarios sobre versiones preliminares de este artículo. 
la revista y también por Ocampo era promover la integración cultural de las "dos Américas", se ha señalado frecuentemente que la verdadera referencia de Sur era Europa, en particular Francia, más que cualquiera de las Américas. Ocampo y su revista han sido denunciados tanto por la izquierda como por la derecha política y cultural por su "europeísmo". Se los ha acusado de tener su mirada fija en Europa (en París en particular) y su espalda vuelta hacia su propio país y hacia su continente. Una rápida mirada al índice de la revista, que continuó saliendo intermitentemente hasta fines de los años setenta, revela que durante la vida de la misma los autores europeos (franceses e ingleses en ese orden, aunque también muchos españoles, en particular exiliados) efectivamente tuvieron una presencia mucho mas conspicua en sus páginas que los oriundos del oeste del Atlántico. Sin embargo la literatura estadounidense y en menor medida la latinoamericana tuvieron una presencia importante en las páginas de Sur, sobre todo durante sus primeros quince años de existencia de la revista. Se podría decir, además, que a lo largo de la vida de Sur las Américas, y en particular los Estados Unidos, ocuparon un lugar problemático dentro de la misma, constituyendo un tema acerca del cual se podía reflexionar y discutir. $^{2}$ América, Argentina y Europa eran tres espacios culturales y geográficos que coexistían a veces de forma tensa como núcleo de las preocupaciones del grupo Sur.

Aunque no me propongo disputar aquí la centralidad de la cultura europea (y en particular francesa) en la empresa cultural de Victoria Ocampo, conviene resaltar que los Estados Unidos ocuparon un lugar cada vez más central en su imaginario y también en su vida real. Nueva York fue reemplazando gradualmente a París como su segundo hogar. Hasta se podría sugerir que Ocampo inauguró una mirada particular hacia los Estados Unidos dentro de la élite letrada argentina. Esta mirada no era la de Domingo F. Sarmiento, quien a mediados del siglo XIX había encontrado ahí un modelo social, económico y político para el futuro de su país, pero tampoco era la de los "dandies" de la generación de 1880, que expresaban su desdén, más tarde combinado con cierto temor, por las tosquedades culturales del coloso del norte. Por otro lado, la visión de Ocampo tampoco puede asimilarse a aquella prevalente durante la era del consumismo, cuando la hegemonía de los Estados Unidos en el mundo se hizo indispu-

2 Esto puede ser visto en los "seminarios" organizados por Sur sobre temas tales como “Tienen las Américas una historia común?”, o "Relaciones Interamericanas”. 
table y cuando ese país se convirtió en el espacio imaginario donde "todo es posible". Para Ocampo, por el contrario, un acercamiento a los Estados Unidos requería un ejercicio de interpretación, y es precisamente de la percepción de esta necesidad de donde deriva la riqueza de su mirada. Sin embargo, la "experiencia americana" de Ocampo también muestra claramente los límites de su posibilidad interpretativa y las tensiones que se originaban de esos límites.

Conviene aclarar que, a pesar de la posición central que Victoria Ocampo ocupaba dentro del grupo que producía Sur, hay que distinguir entre ella y la revista. Aunque sus miembros compartían de manera general una visión del mundo y del lugar que los intelectuales ocupaban (o debían ocupar) en él, como cualquier grupo, el de Sur estaba cruzado por tensiones internas que se ponían muchas veces de manifiesto en la línea editorial de la revista. Aunque tener en cuenta el desarrollo de Sur es esencial para comprender la trayectoria personal de Victoria Ocampo, lo que constituye el eje de este trabajo es más bien esto último. Y esta mirada se justifica en el hecho de que a través de Ocampo, como representante a la vez arquetípica y única del grupo social al que pertenecía, y dada su posición central en el campo intelectual argentino, se puede pensar en términos más generales los alcances y límites del proyecto modernizador promovido precisamente por el sector social e intelectual del cual ella era una representante privilegiada.

\section{Victoria Ocampo, entre Europa y América Latina}

Victoria Ocampo nació en 1890 en el seno de una familia adinerada de la élite porteña cuya presencia en América del Sur podía trazarse hasta el siglo XVI. Su familia había además estado vinculada con los padres fundadores de la nacionalidad argentina. Como ella misma sugería, la historia del país podía contarse a través de la historia de su familia y sus conocidos:

Iba yo a oir hablar de los ochenta años que precedieron a mi nacimiento y en que los argentinos adoptaron ese nombre como de asuntos de familia. La cosa había ocurrido en la casa de al lado, o en la casa de enfrente. San Martín, Pueyrredón, Belgrano, Rosas, Urquiza, Sarmiento, Mitre, Roca, López....Todos eran parientes o amigos. ${ }^{3}$

3 Ocampo, Victoria: Autobiografía, Vol. 1, El archipiélago, Sur, Buenos Aires, 1982, pág. 10. 
Como otros contemporáneos miembros de su clase social, Ocampo fue educada en francés y, en medida algo menor, en inglés. El francés era definitivamente su primera lengua y todavía como adulta escribiría en este idioma y haría traducir algunos de sus escritos al español. Ocampo, de nuevo al igual que otros hijos de la élite local, pasó una parte importante de su niñez en Europa, particularmente en París con su familia. Recordaría décadas después, "los mezclaba [a los himnos nacionales francés y argentino] pues para mí la patria se extendió pronto mas allá de la frontera. No sabía leer. Sabía recordar en dos idiomas que no tardaron en ser tres". ${ }^{4}$ Victoria Ocampo, por lo tanto, creció en un ambiente profundamente europeo y cosmopolita, pero al mismo tiempo sudamericano. De hecho, ella no veía contradicción aparente entre sus profundas raíces argentinas (o más bien sudamericanas) y su cosmopolitismo europeizante; más bien lo contrario: estos dos aspectos de su identidad coexistían en ella aunque en una relación tensa. En una conferencia pronunciada en Italia en 1934, Ocampo reflexionó sobre esta cuestión. Cuando un participante le pidió que hablara sobre temas americanos (en realidad sobre Sudamérica), ella respondió: "soy sudamericana desde hace tantas generaciones que me he olvidado de aparentarlo. No siento la necesidad de disfrazarme de sudamericana, de disfrazar mis pensamientos a la sudamericana y de descubrir América del Sud a cada instante". Y más adelante, "para mí la América del Sud se halla aún a tal punto mezclada a Europa, empapada de Europa —no obstante poseer un carácter propio, cuyos rasgos se acentúan cada día más-, que no es posible evocar a la una sin que la otra surja. Y hay pocos temas americanos en que Europa no se deslice por algún resquicio". ${ }^{5}$ Una década después, Ocampo profundizó en el tema:

"Yo creo que cuando escribo, por ejemplo sobre Emily Bronte o sobre Virginia Woolf, o sobre cualquier otro escritor, lo poco que puedo decir sobre ellos lo digo siempre como americana. Yo pienso además que la cantidad de americanismo que poseo no disminuye en nada por la pasión que siento hacia Europa, sólo que, por el contrario, mi pasión hacia Europa lo enriquece". ${ }^{6}$

4 Ibidem, pág. 8

5 Ocampo, Victoria: "Supremacía del alma y de la sangre", conferencia pronunciada en la Unione Intelletuale de Florencia en septiembre de 1934, en Ocampo, Victoria: Testimonios, Segunda Serie, Sur, Buenos Aires, 1941, pág. 291-92

6 "Debates sobre temas sociológicos. ¿Tienen las Américas una historia común”, Sur, 86, 1941, pág. 102. 
A diferencia de otros miembros de su grupo social, sin embargo, Ocampo desarrolló desde su adolescencia un marcado interés por las letras y por perfeccionar su propia educación. Victoria Ocampo representaba una elite social y económica, pero también intelectual. Y, caso raro en la Argentina de su época, puso su fortuna al servicio de empresas culturales.

\section{Los Argentinos y Estados Unidos}

La "eurofilia"de Victoria Ocampo, ya lo dijimos, era más bien la norma entre la élite educada argentina. El viaje a Europa y el conocimiento de lenguas europeas (en particular el francés) eran elementos esenciales en la educación de la alta burguesía local hasta bien entrado el siglo XX. Los Estados Unidos no estarían incluidos en este itinerario hasta años mucho más recientes. A diferencia de otros latinoamericanos (particularmente mexicanos), para los argentinos, los Estados Unidos no eran considerados ni buenos ni malos vecinos, simplemente no eran vistos como vecinos ni cultural ni geográficamente. Esto no significaba, empero, que los Estados Unidos fueran ignorados, sino más bien que las elites letradas argentinas desarrollaron un complejo patrón de percepciones respecto del país del norte. En la década de 1840 y nuevamente en la de 1860, Domingo F. Sarmiento (quien fuera presidente de Argentina entre 1868 y 1874) había encontrado en los Estados Unidos aquello que había intentado buscar en Europa infructuosamente: un modelo de organización y modernización para la Argentina. Sarmiento creyó encontrar el futuro en los Estados Unidos, y concluyó que el futuro funcionaba. La realización de ese futuro en la Argentina, sin embargo, se retrasaría indefinidamente. Si en 1888, hacia el final de su vida, Sarmiento podía aún predecir que "seremos la América como el mar es el océano. Seremos los Estados Unidos", era porque esta profecía que él ya había formulado décadas antes aún no se había materializado. Algunos decenios más tarde Georges Clemenceau diría que la Argentina era el país del futuro, pero que el problema es que lo sería siempre.

Con la excepción de Sarmiento y algunos otros, sin embargo, los Estados Unidos no eran una referencia cultural para los intelectuales argen-

7 Citado en Tulchin, Joseph: Argentina and the United States: a Conflicted Relationship, Twayne, Boston, 1990, pág. 17. 
tinos, y Nueva York era rara vez incluida en "El Viaje". Cuando lo estaba (y esto comenzó a ocurrir con mayor frecuencia con el advenimiento de la era del avión), la escala en Nueva York era sólo eso, una escala, una especie de plus en el peregrinaje a la verdadera Meca de la cultura: París. En todo caso, la parada en Nueva York se producía por lo general en el tramo de regreso desde Europa. En la década de 1880, cuando la Argentina aún podía con cierto realismo disputar con los Estados Unidos la hegemonía sobre la porción sur del sub-continente sudamericano, los pocos intelectuales que viajaban a los Estados Unidos sospechaban de antemano (y luego, por supuesto, confirmaban) lo poco que ese país podía ofrecer en términos de "cultura verdadera"; para los "gentlemen" argentinos, los yanquis sólo entraban en la categoría de parvenues mercantiles. ${ }^{8}$ Su visión del sur patriarcal y señorial de antes de la Guerra Civil, sin embargo era algo más positiva. Algunos argentinos admiraban el dinamismo norteamericano y su enorme progreso material, pero la mayoría de ellos rechazaba lo que consideraban su exacerbado materialismo y falta de sofisticación. El proyecto de modernización propuesto por las elites argentinas estaba fuertemente vinculado a Europa, su gente y su cultura. Miguel Cané, prestigioso intelectual y político, y miembro de la elite social argentina expresó claramente estos sentimientos a principios de la década de 1880, luego de su viaje por los Estados Unidos, cuando escribía: "un francés del buen mundo con treinta mil francos de renta, hace maravillas, a las que un yanqui con doscientos mil no alcanzaría". ${ }^{9}$

Los argentinos se percibían a sí mismos como mejor educados, mucho más sofisticados y menos preocupados por los asuntos mercantiles y materiales en general que los norteamericanos. Esta visión tenía como contrapartida una política exterior argentina que consistentemente se oponía a los proyectos panamericanos promovidos desde los Estados Unidos y a la creciente hegemonía de ese país sobre el continente. En forma gradual, a medida que los Estados Unidos comenzaron a ejercer su poder sobre las Américas de manera más abierta y brutal, la actitud desdeñosa de los argentinos se fue convirtiendo en temor y preocupación. “¿No ves que esa gente nos quiere tragar?", expresaba en tono de angustia el abuelo de María Rosa Oliver (una cercana colaboradora de Victoria Ocampo en Sur, y ella también

8 Para una perceptiva historia de las percepciones que sobre los Estados Unidos desarrolló la élite argentina, ver Viñas, David: De Sarmiento a Dios. Viajeros argentinos a USA, Sudamericana, Buenos Aires, 1998.

9 Cané, Miguel: En viaje (1881-1882), Ediciones Anaconda, Buenos Aires, 1938, pág. 311. 
miembro de una familia de la elite aunque luego simpatizaría con el Partido Comunista), preocupado por el entusiasmo que su nieta mostraba por Theodore Roosvelt con motivo de la visita de este último a la Argentina ${ }^{10}$. La publicación del influyente libro del uruguayo José Enrique Rodó, Ariel, y el concomitante surgimiento del movimiento "arielista" a lo largo y ancho de América Latina se originaron en este tipo de preocupaciones con lo que ya se percibía claramente como una amenaza imperialista estadounidense. La cultura latinoamericana "más espiritual" y sus tradiciones enraizadas en su pasado hispánico servirían como una barrera contra los asaltos (a la vez políticos y culturales) del norte materialista y desalmado.

Ya en la década de 1920 y aun durante los oscuros años treinta, los Estados Unidos se transformarían para algunos en el espacio imaginario donde todo podría ser posible, el lugar donde los sueños se tornaban realidad y donde los miembros frustrados de la clase media argentina en expansión, desde el escritor Roberto Arlt, hasta el crítico de cine Chas de Cruz podían fantasear con "pegar el batacazo" y revertir su situación. Durante la Segunda Guerra Mundial, para los sectores aliadófilos, Estados Unidos se convirtió además en el último baluarte de civilización frente a la barbarie europea. Lo cierto, y a pesar de todo lo dicho hasta aquí, es que Nueva York continuaba teniendo menos prestigio que París y que los Estados Unidos ocupaban un lugar secundario respecto de Europa en el imaginario de las elites argentinas. Los Estados Unidos eran vistos como un lugar esencialmente destinado al consumo, no a la educación y al cultivo del espíritu. Salvo excepciones, la modernidad norteamericana no atraía a los sectores letrados argentinos. Aún muchos años más tarde, en la década de 1960, cuando Nueva York ya había reemplazado a París como la capital cultural del mundo occidental, los artistas argentinos continuarían viajando primero a París en busca de una educación adecuada antes de ir a Nueva York a efectos de obtener la validación, por otro lado cada vez más necesaria, en el mercado internacional de las artes. Victoria Ocampo encapsuló la percepción que las elites intelectuales argentinas tenían de Nueva York y de los Estados Unidos cuando recordaba en su autobiografía: "Nueva York no era para mí más que una nueva, inmensa ciudad desconocida. Yo solo me siento atraída por aquellas ciudades llenas de recuerdos o sueños personales. Y yo nunca había soñado con Nueva York". " Sin embargo, luego de 1930

10 Citado por Tulchin, Argentina, pág. 24.

11 Ocampo, Victoria: Autobiografía VI. Sur y Cía., Sur, Buenos Aires, 1984, pág. 64. 
Nueva York reemplazaría gradualmente a París como su segundo hogar. De hecho, aun los orígenes de Sur estuvieron muy vinculados a los Estados Unidos a través de Waldo Frank.

\section{Victoria Ocampo, Sur, y los Estados Unidos}

En 1929 el ensayista estadounidense Waldo Frank visitó la Argentina para pronunciar una serie de conferencias. Llegó al país poco después de la partida del conde Hermann Keyserling, otro ensayista muy popular en esos tiempos, con quien Victoria Ocampo había tenido una tempestuosa y traumática relación. El encuentro entre el norteamericano y Ocampo constituyó un punto de ruptura en la trayectoria de esta última, como ella misma reconocería: "Este encuentro marca también un dato importante en mi vida: mi interés por los Estados Unidos, sus escritores, sus ciudades, su "way of life', se me rebeló bruscamente". ${ }^{12} \mathrm{El}$ encuentro de Ocampo con Frank y a través de él con la cultura de los Estados Unidos (o al menos con ciertas áreas de la misma), fue interpretado por ella como un encuentro con lo desconocido. "[Frank] era el primer ejemplar de hombre del Norte de nuestro continente que caía bajo mis ojos (los de mi alma habían visto otros). Hablaba de los Estados Unidos de una manera que me fascinaba". ${ }^{13}$ Este tipo de mirada que podríamos caracterizar como "etnográfica" predominaría en la primera visita que Ocampo haría a los Estados Unidos.

La "historia oficial" de Sur promovida por Ocampo, y repetida luego en muchos lugares, dice que Frank propuso la creación de una revista bajo la dirección de Ocampo y la invitó a los Estados Unidos (país que ella nunca había visitado) para continuar discutiendo el proyecto. El origen de Sur, sin embargo, como demostró recientemente Horacio Tarcus, estuvo muy vinculado no sólo a la figura de Waldo Frank y, desde luego a la de Victoria Ocampo, sino también a la de Samuel Glusberg, editor de la revista La Vida Literaria en Buenos Aires y, en cierta medida, a la del peruano José Carlos Mariátegui. En el contexto de una visita inminente de Mariátegui (quien estaba siendo perseguido por el régimen de Augusto Leguía al punto que la posibilidad de supervivencia de su revista Amauta era incierta) a Buenos Aires, Frank le propuso a Glusberg la creación de una revista que se titularía Nuestra América y que de alguna manera sería la continuadora del pro-

12 Idem, págs. 50-51

13 Idem, pág. 51 
yecto de Amauta. En su visita a Buenos Aires, promovida por Glusberg, Frank conoce a Ocampo y la suma al proyecto. Como diría Frank en su autobiografía: "El aporte de Victoria sería la familiaridad con los clásicos y con las últimas novedades de París y Londres en el campo de las artes y de las letras; el aporte de Glusberg sería su sólido conocimiento de los problemas sociales y de la visión profética de las Américas". ${ }^{14}$ Sin embargo, la alianza entre la aristocrática Ocampo y el intelectual inmigrante judío de izquierda Glusberg no prosperó. Finalmente, luego de la partida de Frank, Ocampo se apropia del proyecto con su círculo de colaboradores y lanza la revista a la que nombra Sur por sugerencia de su amigo José Ortega y Gasset. Para entonces, Mariátegui había muerto y Glusberg quedado al margen del proyecto. ${ }^{15}$

Luego de su encuentro con Frank en Buenos Aires, Ocampo partió para su viaje usual a Europa. Hacia el verano boreal de 1930, y sin estar demasiado convencida, finalmente llegó a los Estados Unidos, construyendo un triángulo cuya dirección solo invertiría tres décadas más tarde (volveremos sobre esto mas abajo): Buenos Aires-París-Nueva York, y no a la inversa. Su llegada a Nueva York no fue gloriosa. Ocampo no se sentía para nada cómoda en este nuevo ambiente: no sabía qué esperar, hacía demasiado calor y su sofisticado vestido francés no era el más adecuado para el clima estival neoyorquino. Sin embargo, muy pronto comenzó a sentir una fortísima fascinación por la ciudad. Su olvido del propósito original del viaje (discutir sobre la revista) obligó a Frank a tener que recordárselo a cada momento.

Ocampo describe la fascinación que sentía por la ciudad de Nueva York en términos casi etnográficos. La crítica Sylvia Molloy utiliza la categoría "orientalismo" acuñada por Edward Said para caracterizar la descripción que Ocampo hacía de sus impresiones sobre Nueva York. Comparaba la ciudad no con París o Londres (ciudades que ella conocía muy bien) sino con Río de Janeiro (ciudad exótica por definición y que, por otra parte, conocía muchísimo menos) en un intento de transmitir el carácter exótico de lo que estaba viendo. Lo que Ocampo percibía de Nueva York en un primer momento era el ruido de los animales proveniente del zoológico del Central Park, rascacielos de proporciones increíbles, una luz que, según

14 Frank, Waldo: Memorias, Sur, Buenos Aires, 1975, pág. 282, citado en Tarcus, Horacio: Mariátegui en la Argentina o las políticas culturales de Samuel Glusberg, El Cielo por Asalto, Buenos Aires, 2001, pág. 48.

15 Ver Tarcus: Mariátegui..., cap. IV. 
ella insistía, no era como la de Europa, ruidos de los autos en las avenidas. Todo, en fin, era diferente y desconocido, aunque no hostil. Y sobre todo estaban los negros de Nueva York, que condensaban el exotismo de la ciudad y que le despertaban contradictorios sentimientos de admiración, desconcierto y prejuicios raciales. Ocampo veía a los negros como un "espectáculo" y todo lo que ellos hacían era interpretado en esos términos. Una noche asistió junto con Frank, el poeta negro Gordon Taylor y el cineasta ruso Sergei Eisenstein (de visita en la ciudad y a quien ella invitaría a Buenos Aires, visita que nunca llegó a materializarse) a un servicio religioso en una iglesia evangélica en Harlem. La excitación que esto produjo en Ocampo se torna evidente en la carta que escribió a su familia inmediatamente después. Empezaba la misma en español, comentando sobre otras cuestiones; pero cuando comenzaba a describir los eventos de la iglesia, cambiaba al francés como hacía habitualmente cuando escribía sobre temas que le provocaban excitación o que la afectaban profundamente. La iglesia, notaba Ocampo, "qui ressemble un peu a un théâtre", "malgré l'aspect comique de ces pauvres nègres", "il m'est impossible de vous l'écrire. Il faudra que je vous le mime", "ce spectacle". Estas eran las expresiones recurrentes que utilizaba cuando quería describir lo que había presenciado esa noche en Harlem. Los negros norteamericanos constituían el "otro" total que encarnaban mejor que nadie la "otredad" de los Estados Unidos. “¿Qué va a pasar?”, preguntaba Ocampo ansiosamente a Gordon Taylor, quien le respondía cada vez: "No sé, ya lo verás".

La correspondencia enviada por Ocampo desde los Estados Unidos destilaba un sentimiento sensual de desconcierto y fascinación frente a lo desconocido. Desde el principio queda claro que para ella Nueva York no era como París, pero que, al mismo tiempo, tampoco era como Buenos Aires. Nueva York era algo diferente y por lo tanto no tenía sentido hacer comparaciones. Comprender a los Estados Unidos requería el uso de nuevas categorías analíticas. El momento fundacional de esta nueva relación con la ciudad (y por extensión con el país, aunque así como Francia era París, Estados Unidos era para Ocampo Nueva York aunque había recorrido otras zonas del país) tuvo lugar cuando visitó el estudio y galería del fotógrafo Alfred Stieglitz en Manhattan, llamado "An American Place". El momento estuvo encapsulado en un pequeño episodio cuando Stieglitz, mirando a través de la ventana de su estudio la ciudad de Nueva York, dijo: "¿Es eso belleza? No lo sé. No me importa. Yo no uso la palabra belleza. Es vida"; y Victoria Ocampo: "An American Place...Jamás se me había 
ocurrido que un oasis pudiera tener ese nombre. Felicidades de esas ya no se esperan". ${ }^{16}$ Este episodio permaneció en su mente y sería revisitado dos décadas después: "Y yo apliqué a nuestra América del Sur lo que Stieglitz me dijo mirando los rascacielos de Manhattan a través de la ventana". ${ }^{17}$ Debe recordarse que Stieglitz, marido de la pintora Georgia O'Keefe, era en sí mismo una especie de bisagra entre las culturas norteamericana y europea. Se lo considera uno de los padres fundadores del modernismo estadounidense en fotografía y, al mismo tiempo, como el introductor del arte moderno europeo en el mercado artístico de su país, lo que era apreciado por la escritora argentina.

Pero, como señala Beatriz Sarlo, Nueva York también le permitía a Ocampo, pensar sobre Buenos Aires y sobre las Américas en general de una manera renovada. La relación que había establecido desde su niñez y juventud entre Buenos Aires por un lado y ciudades como Londres y París por el otro, estaba caracterizada por una clara asimetría. Estaba claro que Europa era lo que Argentina no era, y que esas ciudades en particular eran lo que Buenos Aires no era ni podía ser. Nueva York, por otro lado, tampoco tenía lo que París, y sin embargo era fascinante en sus propios términos. "New York le enseña [a Ocampo] otra posibilidad americana de la cultura", ${ }_{18}$ escribe Sarlo. De hecho, según esta autora, Ocampo logró establecer todo un nuevo tipo de relaciones con América del Norte y sus intelectuales, un tipo de relación más igualitario del que jamás haya podido establecer con los intelectuales europeos. A pesar de su cosmopolitismo, de su dominio casi nativo del idioma francés y de su dinero, Ocampo era vista en París como una grand dame de la periferia. En cambio, si era capaz de hacer esfuerzos por entender a los Estados Unidos y a sus intelectuales en sus propios términos, también era cierto, nos dice Sarlo, que Waldo Frank y otros podían entender a Ocampo en sus propios términos, posibilitando de esta manera un nuevo tipo de relación. Tal como ella recordaría décadas después: "Sentíamos en él [en Frank] un fervor auténtico por todo lo americano, del norte y del sur. Tal vez más aún del sur... Nosotros no estábamos acostumbrados a una actitud semejante en escritores norteamericanos o europeos....Eso nos halagaba y conmovía". ${ }^{19}$

16 Ocampo, Victoria, Testimonio. Primera serie, Revista de Occidente, Madrid, 1935, pág. 393.

17 Ocampo, Victoria, "Vida de la revista Sur. 35 años de una labor". Sur, 303-304-305, Noviembre 1966-Abril 1967, pág.10.

18 Sarlo, Beatriz: La máquina cultural: maestras, traductores y vanguardistas, Ariel, Buenos Aires, 1998, pág.135.

19 Ocampo, Victoria: Testimonios. Séptima serie, 1962-67, Buenos Aires, Sur, 1967, pág. 177. 
La comprensión mostrada por Frank respecto del proyecto de Sur contrastaba con la incomprensión mostrada por los amigos franceses de Ocampo, quienes le preguntaban hasta qué punto la revista tornaría su espalda a la cultura europea. "iSencillamente porque declaré que su fin principal [de la revista] consistiría en estudiar los problemas que nos conciernen, de un modo vital a los americanos! ¡Volver la espalda a Europa! ¿Siente el ridículo infinito de esa frase?", preguntaba Ocampo a Waldo Frank en la carta con la que abría el primer número de Sur. Los europeos era incapaces de entender el proyecto..$^{20}$

Si uno mira con cuidado los intercambios epistolares y de otro tipo entre Ocampo y Frank, empero, es posible percibir aun allí (aunque sin duda de una manera más matizada) asimetrías bastante similares a las que Sarlo detecta en las relaciones entre Ocampo y los intelectuales europeos. En 1942, por ejemplo, Frank visitó la Argentina por segunda vez. La visita formaba parte de un programa de intercambio intelectual establecido por el gobierno de los Estados Unidos en el contexto de su política de "Buena Vecindad". Esta vez, sin embargo, la estadía de Frank en la Argentina terminó mal. Judío, izquierdista y estadounidense, fue agredido físicamente por un grupo de nacionalistas de derechas, y luego expulsado del país por el gobierno, que por entonces miraba con bastante simpatía a las potencias del eje. En el banquete de recepción, Victoria Ocampo utilizó la oportunidad para comunicarle a Frank, una vez más, que "la América de ellos y la mía son, en nuestro sentir y en nuestra voluntad, la misma América".

La respuesta de Frank, aunque navegando en aguas parecidas, reflejaba una visión que era obviamente diferente. Luego de saludar a su anfitriona como la "verdadera reina de América del Sur" (¿una "reina nativa"? podríamos preguntarnos nosotros), Frank pasó a detallar la lista de cosas que él admiraba de la "América de ella": la música, la comida (sobre todo la comida), las danzas, "vuestros temperamentos complejos e infinitamente variados, tan fuertes como vuestros Andes, y sin embargo, tan sutiles como las perspectivas de vuestra Pampa". Frank había descubierto en el "mundo hispánico" (que incluía no solo a América Latina desde Mexico hasta la Argentina, sino también a España), la dimensión perdida de "su" América (la de él).

Era la sensación que nosotros, precisamente los de los Estados Unidos, civilización desequilibrada por las máquinas, dirigidas por hombres de cabezas de máquina, y

20 Ocampo, Victoria: “Carta a Waldo Frank", Sur, 1, verano de 1931. 
gastados por la máquina, necesitábamos una nueva capacidad de integración para que no se hiciera pedazos la total estructura de la civilización: necesitábamos un manantial de fuerza para la integración y conocimiento esencial que el mundo hispánico y el indohispánico parecían poseer. ${ }^{21}$

Esta evidente asimetría (civilización en el norte, conocimiento esencial en el sur), era, sin embargo, mucho mas sutil de la que se percibía entre Ocampo y su cultura, por un lado, y los europeos y la suya, por el otro. Con ellos estaba muy claro dónde se ubicaba el "centro": en París. La "mirada etnográfica" solo podía ser aplicada en una dirección. Con los norteamericanos, empero, la situación era diferente porque para ambos el centro estaba ubicado en otra parte: aún en Europa (al menos hasta la década de 1940). Por lo tanto, las dos partes del continente, la norte y la sur, admitían que se les aplicara el tipo de mirada que Frank de alguna medida había practicado en Buenos Aires y que Ocampo no se privaría ella misma de practicar en Nueva York. Sin embargo, esta relación, conviene destacarlo, distaba de ser totalmente igualitaria.

El descubrimiento del norte además le permite a Ocampo un redescubrimiento del sur: "Mi primer contacto con el Norte de nuestro continente en 1930 produjo la consecuencia imprevista de hacerme descubrir el Sur tanto como ese norte", recordará Ocampo en su autobiografía. ${ }^{22}$ El conocimiento que se originaría en esta relación entre "las dos Américas" - lo que se podría llamar el americanismo de Sur y de Ocampo-, era, sin embargo, limitado. Tal como señala Sarlo, este americanismo no se hacía cargo de la "desigualdad y la violencia que separan a América Latina de Estados Unidos (este punto ciego define así una ideología y una política)". ${ }^{23}$

Lo que se reveló ante los ojos de Victoria Ocampo durante su primer viaje a los Estados Unidos es que había otra América posible, una cuyos contrastes con la propia se condensan en la descripción que ella hacía del Canal de Panamá: "La limpieza florida de los barrios yanquis con su césped regado y las heladeras blancas (símbolo de la civilización norteamericana) que se entreveían por las ventanas; y del otro [lado] los malos olores, las vestimentas de la gente, sus casas, la soñolencia, la inercia, el desaseo que por puertas o balcones parecían volcarse a la calle... recordaba la reacción de Chaplin: 'Si no valemos más que para esto, peor para nosotros.

21 "Waldo Frank en Buenos Aires", Sur, 92 ,1942, pág. 92.

22 Ocampo: Autobiografía, VI, págs, 67-68

23 Sarlo, Beatriz: "La perspectiva americana en los primeros años de Sur", Punto de Vista, VI, 17, abril-junio de 1983, pág. 11. 
Reventemos', pensaba". ${ }^{24}$ Ocampo hacía explícita la tensión que sentía dentro de ella misma como resultado del descubrimiento de su propia América a través del lente de la "otra" América. Y Ocampo escribía a Ortega y Gasset desde Lima en su viaje de retorno desde los Estados Unidos: "No puedo explicarte hasta qué punto me ahogan sentimientos contradictorios. Me parece que voy a estallar. Por un lado, los yanquis terriblemente eficaces y a veces limitados (en ciertos aspectos), pero capaces de transformar lugares inhóspitos y hacer que se pueda vivir en los sitios más dejados de la mano de Dios; por otro lado los panameños, los peruanos ["y allí más lejos, al Sur, nosotros" agregaba Ocampo en la versión publicada de la carta treinta años después], miserables e incapaces en comparación". ${ }^{25}$ A efectos de calmar la ansiedad que le producía su descubrimiento simultáneo del Norte y del Sur y de sus aparentemente infranqueables diferencias, Ocampo buscó refugio en lo que conocía mejor: Europa. "Luego de una hora de paseo por las calles de Antofagasta, volví al Santa Clara y me encerré en el camarote. Puse un disco de Debussy y metí la cabeza en el fonógrafo. Durante una hora escuché.... Debussy= Oxígeno= Europa". La simplicidad de esta visión dicotómica del Norte y del Sur sería matizada, y la percepción ganaría en complejidad a lo largo de los años subsiguientes.

Victoria Ocampo no retornaría a los Estados Unidos por trece años. En 1943, en el medio de la Segunda Guerra Mundial, fue invitada por la Fundación Guggenheim a visitar el país por seis meses, la mayoría de los cuales pasó en la ciudad de Nueva York. Según Sylvia Molloy, es en este viaje cuando se tornan evidentes los límites de la relación de Ocampo con los Estados Unidos. Durante esta segunda estadía en ese país pasó la mayor parte de su tiempo junto a exiliados franceses. Sus cartas a su antiguo amante y protegido Roger Caillois (él mismo un exiliado francés en Buenos Aires) desbordan de nostalgia por París: "Nada de lo que siento, nada de lo que amo es atractivo para este país. Eso me hace sentir deprimida, pero sé que es estúpido esperar otra cosa". ${ }^{26} \mathrm{El}$ tono de estas cartas, sin embargo, contrastan fuertemente con las impresiones transmitidas por ella en un texto escrito un año después del viaje para ser publicado: USA, 1943. A diferencia de sus cartas íntimas, en este texto mostraba un nivel de familiaridad con la ciudad de Nueva York y una comodidad con la misma

24 Ocampo: "Vida de la revista", pág. 6.

25 Idem., pág. 5.

26 Carta de Victoria Ocampo a Roger Caillois, junio 26 de 1943, en Ocampo, Victoria y Roger Caillois: Correspondencia (1939-1978), Sudamericana, Buenos Aires, 1999, pág. 143. 
que marcaban un fuerte contraste con el "orientalismo" presente en sus cartas de 1930. Esta familiaridad además se complementaba con un sentimiento de admiración por lo que los Estados Unidos representaban en 1943. Como recordaba en su autobiografía: "Los rascacielos y los puentes me gustaron inmediatamente. Pero New York no me deslumbró realmente sino cuando volví en 1943. En 1930 París, Londres, se interponían entre New York y yo, sin que me diera cuenta plenamente. Comparaba todo. Y no hay nada que comparar. Se trata de otra cosa. Y a otra escala". ${ }^{27}$ Las cartas a Caillois, empero, muestran otro tipo de sentimientos.

En USA 1943, Ocampo expresaba su amor por los Estados Unidos, incluida por su comida y, sobre todo, el texto mostraba un esfuerzo de comprensión por parte de la autora. Es suficiente hacer una comparación entre las impresiones transmitidas luego de su primera visita a Harlem en 1930 (un "espectáculo") con las que le originan su visita en 1943 a los "heavens" de Father Divinity. Esta vez lo que llamaba la atención de Ocampo era la limpieza, honestidad y devoción de los fieles (todos negros, desde luego), así como también la calidad de la comida. No había lugar para espectáculos esta vez. ${ }^{28}$ De manera semejante, Ocampo hacía explícito su reconocimiento de la necesidad de nuevas categorías para entender y apreciar lo que los Estados Unidos tenía para ofrecer y que ella cada vez descubría con más entusiasmo:

\footnotetext{
No creo que los norteamericanos sean mejores que el resto del mundo, pero tampoco creo que la falta de trufas sea en ellos síntoma de mal aguero. ¿Para qué hacer el paralelo entre la Plaza de la Concordia y los rascacielos de la Quinta Avenida?... La belleza del pez no es la del pájaro. Por desgracia, hay muchos que odian lo que en Estados Unidos es diferente de Europa, es decir, casi todo. ${ }^{29}$
}

Lo que Ocampo estaba descubriendo es que los Estados Unidos podían ser apreciados y hasta amados en la medida que esto se hiciera en sus propios términos.

Pero, por otro lado, las cartas a Caillois, ya lo vimos, destilaban un sentimiento muy diferente por la ciudad y por el país. Nueva York era caracterizada en ellas como una ciudad esencialmente melancólica. Esta melancolía estaba representada por la presencia ubicua de los exiliados

27 Ocampo: Autobiografía, VI, pág. 81. Mayúsculas en el original.

28 Ocampo, Victoria: Testimonio. Tercera serie, Sudamericana, Buenos Aires, 1946, págs.22728. La versión de USA 1943 que utilizo es la que aparece publicada en este texto.

29 Idem., pág. 265. 
franceses y, de una manera aún más patética, por el buque Normandie, ese ícono francés de un pasado de gloria que casi se hunde en el puerto de Nueva York como una metáfora de ese presente menos que glorioso. De acuerdo con la visión de Molloy, lo que Nueva York evocaba en Ocampo durante esta segunda visita no era la lejana Buenos Aires, ni la Nueva York de diez años antes, sino París borrada por la guerra. Si Sarlo sugiere que los Estados Unidos constituían un espacio donde la asimetría existente en la relación de Ocampo con Europa podía disolverse en un vínculo más igualitario, para Molloy los Estados Unidos constituían un límite, o mejor dicho una frontera para Ocampo. El referente sería siempre Europa. Sin embargo, la situación no parece haber sido tan clara. Me gustaría argumentar que los sentimientos por Nueva York que Ocampo expresaba en sus cartas a Caillois (con quien compartía una memoria específica sobre París) estaban en buena medida condicionados por factores históricos precisos y no tanto por los límites de su comprensión de los Estados Unidos.

En 1943, Ocampo ya era una mujer de cincuenta y tres años, y retornaba a Nueva York, una ciudad que no había visitado en trece años y en la que sólo había estado una vez antes. París, la ciudad en la que había crecido, parecía perdida para siempre, y al mismo tiempo vestigios nostálgicos de la misma podían verse en todas partes en Nueva York, desde el Normandie en decadencia (o el Richelieu, lleno de banderas francesas), hasta los numerosos exiliados para quienes la experiencia americana ocuparía un lugar importante en su vida intelectual futura ${ }^{30}$ Pero en este segundo viaje también se tornó evidente para ella que el centro del mundo (y también el de su imaginario) se había desplazado. Sólo se puede sentir nostalgia por aquello que está irremediablemente perdido, y esto era claro para ella:

En 1943...la situación de Francia era trágica. Al encontrarme con la tapicería del Unicornio en los Cloisters y después, en Chicago, con los ojos de las mujeres de Renoir... casi había soltado el llanto. Esas salas asépticas de museos, relumbrantes de limpieza como salas de operaciones me helaban. Francia estaba allí, pero como en un ataúd. Ya era Grecia ${ }^{31}$.

Por supuesto, aunque ella no lo decía explícitamente, si Francia era Grecia, Estados Unidos era Roma. Ocampo tomaba conciencia de que buscar un París vivo en Nueva York era un ejercicio inútil. Apreciar lo que los

30 Ver Mehlman, Jeffrey: Emigré New York: French Intellectuals in Wartime Manhattan, 19401944, Johns Hopkins University Press, Baltimore, 2000.

31 Ocampo: Testimonios. Séptima serie, pág. 131. 
Estados Unidos tenían para ofrecer, empero, requería un aprendizaje de su parte. Recordando ese primer encuentro fundamental con Stieglitz, narraría el episodio años más tarde para concluir: "iQuién lo duda, mi querido Stieglitz! La belleza ha nacido junto con la vida en tu desconcertante país... Yo he aprendido no sólo a admirar sino también a amar a los Estados Unidos, esto es lo que quiero decir sin más demora". ${ }^{32}$ Sólo luego de este proceso de aprendizaje, Ocampo pudo concluir que la vida estaba al oeste del Atlántico.

Tras de este segundo viaje a los Estados Unidos, muchos otros seguirían. A través de la correspondencia que enviaba a su familia y amigos es claro que se sentía cada vez más cómoda en sus estadías, por otro lado más prolongadas y frecuentes, en el país del norte. De hecho se puede decir que Nueva York fue reemplazando a París como su segundo hogar. De la misma manera el idioma inglés también comenzó a aparecer con mayor frecuencia en sus cartas. Incluso se puede percibir al respecto que establecía una especie de triangulación. Escribía en francés desde y sobre Nueva York, y en inglés desde y sobre París. Le gustaba el confort americano, la prosperidad americana y aun la comida americana (llega a decir que le gusta la cocina de los Estados Unidos con preferencia de cualquier otra cocina, incluyendo la francesa). Su insistencia con el tema de la comida podría ser leído como una metáfora de su necesidad de "tragar"o "digerir" a los Estados Unidos. En otras palabras, a Ocampo le gustaba la modernidad norteamericana, una modernidad por cierto bien diferente de la europea y que ella sólo pudo apreciar después de un proceso consciente de aprendizaje. Encontraba el Museo Guggenheim feo pero moderno, eficiente y bien organizado; mientras que la Hispanic Foundation en Nueva York, representante del "mundo latino" en el norte, era descrita, en lo que casi constituía una imagen especular, como una institución desorganizada, sucia y definitivamente ineficiente. Si en 1943 había dejado caer sus lágrimas cuando vio los tapices del Unicornio en los Cloisters, hacia 1959 había aprendido a disfrutar de los Cloisters tal como eran y en sí mismos. Los Cloisters son perfectos, nos dice Ocampo, no hay falta de buen gusto allí. Aun los baños son perfectos porque están equipados con todo lo que las mujeres necesitan cuando están menstruando "y no dejo de admirar esas pequeñas $\operatorname{cosas"}^{33}$. La utilización de la doble negación "no hay falta de buen gusto",

32 Ocampo: Testimonios. Tercera serie, pág. 215. Énfasis mío.

33 Carta de diciembre 21, 1959 en Ocampo, Victoria: Cartas a Angélica y otros, Buenos Aires, Sudamericana, 1997, pág. 111. 
sin embargo muestra la tensión existente todavía en la percepción que Ocampo tenía de los Estados Unidos. Pareciera que la falta de buen gusto era lo que ella, por definición, esperaba encontrar allí.

Si el encuentro de Ocampo con Stieglitz había tenido un carácter fundacional, su viaje de 1963 constituyó otro mojón de importancia en sus relaciones con los Estados Unidos. Esta vez, invirtiendo la dirección usual del triángulo establecido décadas atrás, se dirigió primero a Nueva York y después a París, desde donde escribe a su hermana Angélica:

Hacía tiempo que no llegaba de NY a París (generalmente salgo de aquí para allá). La impresión es distinta. Lo que se nota al entrar (y circular) en la Gare St Lazaire (ya) es otro nivel económico, deficiencias patentes, suciedad, barullo. Y al pasar por las calles de París, ídem. Otro nivel de vida, aunque el movimiento de autos es grande (los mismos autos parecen de otro nivel, dans l'ensemble)... Las calles, preciosas siempre son (dado lo que traigo en mis ojos) las de una maravillosa ciudad de provincia deslumbrante... Las comparaciones son odiosas, pero se nos imponen. París es Roma... incomparable pero...pièce de musée, en cuanto a la época contemporánea cuyo "exponente" sería New York. El poderío de los Estados Unidos es tremendo y Nueva York lo encarna. ${ }^{34}$

La sustitución de Nueva York por París —esta última ciudad ahora degradada al rango de "ciudad de provincia" - no era aún completa y desde luego el proceso reflejaba tensiones que, se podría argumentar, eran de alguna manera inherentes a la cultura de la élite argentina. Sin embargo, Ocampo defendía enérgicamente a los Estados Unidos del antiamericanismo francés (y argentino). De esta manera respondía a un comentario hecho por el crítico español Guillermo de Torre (cuñado de Jorge Luis Borges y estrecho colaborador de Ocampo en Sur) acerca de películas norteamericanas: "Si todo lo que he visto y oído en USA (qué orquestas, qué teatros, qué puentes, qué parques, qué bibliotecas públicas, qué museos, qué helado de crema) es el resultado de "la civilización de la Coca-Cola" (que no bebo), ¡Viva la Coca-Cola!”. ${ }^{35}$ Hay que señalar, empero, que sus propios comentarios sobre los Estados Unidos muchas veces incluyen descripciones de estadounidenses borrachos y estólidos que ciertamente es muy improbable que jamás hayan puesto un pie en los museos y bibliotecas que tanto admiraban

34 No está claro si ésta fue en realidad la primera vez que Ocampo viajó de esta manera. Lo que parece claro es que ésta sí fue la primera vez que ella era consciente acerca de este cambio de itinerario y que por lo tanto extrajo consecuencias del mismo. Ver carta a Angélica y Pancha desde París, 21 de noviembre de 1963. Ocampo: Cartas, págs. 151-152.

35 Ocampo: Testimonios. Cuarta serie, Buenos Aires, Sudamericana, 1950, pág. 232. 
a Ocampo, pero que muy probablemente comían helado y tomaban Coca Cola. La lista (que podríamos caracterizar de ecléctica) de las cosas que Ocampo admiraba de los Estados Unidos refleja también la existencia de una tensión en sus sentimientos (y recordemos además que para Ocampo los Estados Unidos estaban por lo general limitados a la ciudad de Nueva York). París continuaba siendo el locus de la "alta cultura", cultura restrictiva. Pero en términos de los lugares que de alguna manera modelaban de manera más general las visiones del mundo, lo que podríamos llamar "cultura" en un sentido mas amplio, Nueva York estaba claramente tomando precedencia.

Sylvia Molloy ha enfatizado la marginalidad de Victoria Ocampo en Nueva York. Esta autora señala que, aunque es cierto que Ocampo viajaba cada vez con mayor frecuencia (y por períodos más largos) a Nueva York luego de 1943, sus contactos con la ciudad eran más bien superficiales. El círculo social de Ocampo en Nueva York, nos dice Molloy, se reducía en general al grupo de exiliados o ex-exiliados. La soledad que sentía en Nueva York era evidente. Me gustaría proponer, en cambio, una visión alternativa. Mi hipótesis es que los Estados Unidos no constituían un límite para Victoria Ocampo, sino más bien un espacio donde los límites inherentes a su proyecto de modernidad o, podríamos decir, los de su clase social, se hacían evidentes. Cuando ella comienza a visitar Nueva York regularmente, ya no era una mujer joven. Además, probablemente por primera vez en su vida comenzaba a tener ciertos apremios financieros. El precio de las cosas en Nueva York, y los esfuerzos que debía hacer a efectos de mantener su nivel de vida, se convirtieron en temas centrales de su correspondencia. Si décadas antes Ocampo había literalmente cubierto a Virginia Wolf con regalos carísimos (al punto que esta última se había mostrado desconcertada e incómoda), ahora en Nueva York, mostraba su preocupación por el precio de un bouquet de flores con el que quería obsequiar a Vera Strawinsky. Descubría además que el valor de la moneda argentina era cada vez más débil. Estas preocupaciones con el dinero ya habían estado presentes en las cartas que enviaba a Caillois en 1943: "Esta vida me está arruinando, aun si vivo una vida muy simple; estoy cerca de la bancarrota porque como carne, porque mi ventana se abre al Central Park, porque tengo una habitación extra para recibir a la gente que viene a verme, porque a veces los invito a cenar, porque estuve enferma, y porque estoy acostumbrada a vivir como me has visto vivir, y aquí es necesario ser un multimillonario para vivir de esa manera". ${ }^{36}$

36 Carta de Victoria Ocampo a Roger Caillois, 21 de agosto de 1943. En Ocampo y Caillois: Correspondencia, pág. 146. 
Pero además y fundamentalmente, el mundo cambiaba rápidamente y también el lugar que Victoria Ocampo ocupaba en él. Sus interlocutores naturales iban perdiendo la relevancia que ocuparan otrora. Cuando comenzó a frecuentar los Estados Unidos, el país y la posición de los intelectuales dentro de él estaban sufriendo una profunda transformación. Su contacto original con los Estados Unidos, Waldo Frank, pertenecía a la última generación de intelectuales norteamericanos de "estilo europeo", intelectuales norteamericanos que, después de la Segunda Guerra Mundial, serían rápidamente reemplazados y desplazados por académicos profesionales. Este campo intelectual estadounidense redefinido era muy poco hospitalario para intelectuales como Victoria Ocampo, como ella misma constataba dolorosamente. Sin embargo, si su lugar en los Estados Unidos estaba destinado a ser cada vez más periférico, lo mismo puede decirse del que ocupaba en Europa, y aun en su amada París. A medida que sus amigos de juventud iban muriéndose, debía afrontar en París la misma soledad que en Nueva York. Si en Nueva York ella buscaba alivio para este sentimiento de soledad en los cines, lo mismo pasaba en París. Excepto que aun en París ella mostraba su preferencia por las películas norteamericanas. Y escribe desde París en 1963:

Anoche fui a ver Detective Story que daban en un cine de Champs Elysée (no voy sino a los cines de ese barrio que es el mío). Había visto, días anteriores, films franceses detestables. Entre otros uno de Francoise Sagan. Pero lo que se llama detestables. Cuando vi las calles de New York y aparecieron los americanos, y hablaron y se movieron en la pantalla fue como si respirara aire fresco y volviera a casa. ¡Ay que cerca de ellos me sentí! ¿Qué pasa, qué pasa aquí? Aquí donde hay tanta belleza y tanto refinamiento y... tanta decadencia... Porque decadencia y atraso hay. Esto, recuerdas Angélica, lo he sentido hace años y años. Con todo... ¡Que encanto París! Pero veo las calles de New York y respiro. Aquí no los quieren a los americanos. Yo sí. Son el mundo de hoy. No hay vuelta que darle. Y que revienten los envidiosos (que de envidia se trata)... Esta ciudad ha sido mi casa. Lo es. Pero la veo decrépita en su máxima belleza. Quiero decir que no está al día, que se ha quedado en otro siglo. ${ }^{37}$

Si en 1930, en su camino de retorno de su primer viaje a los Estados Unidos, Ocampo había buscado "oxígeno" en la música de Debussy, oxígeno que le permitiría digerir las nuevas sensaciones que estaba experimentando; ahora el "aire fresco" provenía de las imágenes de las calles de Nueva York. La ciudad de Nueva York y más generalmente los Estados Unidos eran el mundo de hoy y encarnaba una modernidad bien distinta de

37 Carta desde París, diciembre de 1963. Ocampo: Cartas, pág. 175. Enfasis mío. 
la europea. París era la belleza de los museos, de un mundo irremediablemente perdido al que Ocampo era demasiado lúcida como para intentar aferrarse demasiado fuertemente. El mundo de intelectuales dandies de entreguerras en el que ella había florecido y alrededor del cual había podido tejer sus redes de relaciones internacionales y que en todo caso constituían sus interlocutores se estaba evaporando y ella lo sabía. En París aún visitaba a Malraux, otro vestigio de una era anterior ahora reciclado como ministro del gobierno de De Gaulle. Pero sus amigos de décadas pasadas o bien habían muerto (Albert Camus, Pierre Drieu la Rochelle), o bien se habían integrado en (o más bien en algunos casos iban a la vanguardia de) el nuevo ambiente intelectual de una manera en que ella no podía seguirlos. Este era el caso, por ejemplo, de Jacques Lacan, a quien había conocido en los años 30 y con quien había trabado una relación bastante estrecha. Podríamos decir que los Estados Unidos representaban para Ocampo la apertura de un nuevo mundo, pero también el cierre de uno antiguo.

Tras de la caída del régimen de Perón en 1955, en el renovado ambiente cultural en el que ya se podían intuir elementos que caracterizarían a los años sesenta, Sur, la revista que a lo largo de tres décadas había ocupado un lugar central en el campo de producción y difusión de cultura en la Argentina, comenzó rápidamente a perder relevancia. Aunque en 1955 todavía seguía siendo la publicación literaria más prestigiosa del país, ya era evidente que no estaba en condiciones de seguir el rápido proceso de modernización cultural que comenzó luego de la caída del gobierno de Perón $^{38}$. Este prestigio se había basado en la densa red de conexiones internacionales que Victoria Ocampo había logrado generar a su alrededor, y en el hecho de que la revista llegó a convertirse en el portavoz privilegiado de una elite intelectual cuyos miembros habían logrado jugar un papel importantísimo como agentes de legitimación dentro del campo de producción de cultura. Sur pertenecía a una era en la que los intelectuales se percibían a sí mismos como una elite internacional que operaba de acuerdo a sus propias reglas y con un nivel relativamente alto de autonomía respecto de la política y de otros intereses. Esto explica en parte, por ejemplo, por qué Victoria Ocampo, cuyas simpatías liberales y pro aliadas durante la guerra eran claras y explícitas, pudiera al mismo tiempo ser la amante del escritor

38 Ver King, John: Sur. Estudio de la revista argentina y de su papel en el desarrollo de una cultura, 1931-1970, México, Fondo de Cultura Económica, 1989, pág. 207. Sobre el desarrollo de la cultura argentina durante los 60 y en particular sobre el papel de los intelectuales, ver Sigal, Silvia: Intelectuales y poder en la década del sesenta, Buenos Aires, Puntosur, 1991. 
derechista Pierre Drieu la Rochelle, quien durante la ocupación alemana colaboraría con los nazis y quien luego de la Liberación se salvó de ser ejecutado gracias a la intervención firme y directa de Malraux (lo cual también puede ser interpretado como un síntoma de los tiempos), sólo para suicidarse poco después. Esta relación con Drieu no era solamente íntima, ya que el nombre del escritor francés figuraba en el comité editorial internacional de Sur, en sus inicios, aunque luego fuera removido al tornarse inaceptable sus simpatías políticas.

Durante la década de 1960 la posición que el grupo Sur se había construido dentro del campo intelectual era mucho mas difícil de mantener. A medida que los miembros del grupo original alrededor del cual se había construido el proyecto envejecía, una nueva generación de escritores tanto en Argentina como en América Latina en general los fueron desplazando en un contexto de creciente politización de la cultura. Como resultado de esto, Sur también fue desplazada políticamente. Desde su aparición a principios de los 30, la revista (y Victoria Ocampo) habían apoyado todas las "causas buenas": el lado republicano durante la Guerra Civil Española (aunque tibiamente al principio), y mucho más clara y decididamente la causa de los aliados en la Segunda Guerra Mundial. Durante el gobierno de Perón, aunque referencias directas a la situación argentina estuvieron ausentes de las páginas de Sur, el feroz anti-peronismo del grupo era conocido. Críticas indirectas pero muy fuertes contra el régimen podían ser descubiertas en Sur por cualquiera que quisiera leer entre líneas. Tanto Borges como Victoria Ocampo fueron castigados por el gobierno de Perón, y Ocampo en particular fue brevemente encarcelada sin que se formularan jamás cargos concretos en su contra. Durante años Sur había encarnado el proyecto modernizador de una élite intelectual liberal. El problema es que ese proyecto perdió ímpetu en los años sesenta.

De alguna manera, la revista y el proyecto que la sostenía encarnaban el liberalismo clásico (o al menos así era percibido) en momentos en que el liberalismo como proyecto estaba siendo cuestionado tanto por la derecha como por la izquierda, y cuando en particular las interpretaciones canónicas del peronismo originadas en ese liberalismo estaban siendo revisadas por una nueva generación de jóvenes intelectuales progresistas ${ }^{39}$. Además Sur le volvía la espalda al latinoamericanismo y sobre todo a la Revolución Cubana, ambos íconos culturales de los sesenta. En la emergente cultura de

39 Algunos de ellos, encabezados por los hermanos Ismael y David Viñas, se concentraron alrededor de la revista Contorno, publicada entre 1953 y 1959. 
masas introducida por el peronismo y que luego adquirió dinámica propia había poco espacio para el tipo de elitismo cultural encarnado por el grupo Sur y para el tipo de intelectual por él promovido. El gobierno de Perón y sus sucesores expandieron dramáticamente el acceso a la educación superior, y la cultura también se convirtió en objeto de consumo. Ciertos libros se convirtieron en objetos de culto para una clase media intelectual en expansión. Eran los años del "boom literario", cuando algunos autores, en palabras de John King, se convirtieron en verdaderas "marcas de fábrica". Victoria Ocampo no podría esconder el desconcierto que estos desarrollos le provocaban:

Al mismo tiempo, hecho insólito, el vulgo compra las obras de Cortázar (tan luego de Cortázar) y se pasea con sus libros en Torino o en subte o en colectivo. Sin embargo, Cortázar es netamente un autor para minorías, no para lectores a quienes ha de aburrir fabulosamente.... porque no están preparados para digerirlo y saborearlo. Y que nadie se me ofenda. Frente a la máquina ( $\sin$ ir más lejos la de mi auto, que manejo) soy el vulgo, y requetevulgo. ${ }^{40}$

Era claro que Sur no podía encontrar su lugar en un mundo que cambiaba tan rápidamente.

Algunos aspectos del proyecto de Victoria Ocampo, sin embargo, fueron recuperados años más tarde en un contexto completamente diferente y sobre todo con interlocutores diferentes. En 1978, cuando la Argentina era gobernada por una de las más sangrientas dictaduras militares que jamás haya existido al oeste del Atlántico, otro grupo de intelectuales jóvenes y brillantes, liderados por otra mujer, Beatriz Sarlo, crearon una nueva revista de cultura, Punto de Vista, que existe hasta el día de hoy. ${ }^{41}$ Punto de Vista se ha convertido en una de las publicaciones más prestigiosas y reconocidas de su tipo en la Argentina. Los antecedentes sociales de los miembros del grupo editor de Punto de Vista no pueden ser más diferentes de los de los creadores de Sur. Sarlo y sus colaboradores pertenecen a la clase media universitaria y en parte son producto del "academicismo" creciente de la vida intelectual de los 60. Durante las décadas de 1960 y 1970 todos ellos

40 Ocampo, Victoria: "Después de cuarenta años" Sur, pág. 325 (1970), citado en King, Sur, pág. 212

41 Para una discusión detallada del origen y desarrollo temprano de Punto de Vista, ver Plotkin, Mariano y Ricardo González Leandri: "El regreso a la democracia y la consolidación de nuevas élites intelectuales. El caso de Punto de Vista. Revista de Cultura. Buenos Aires (1978-1985)" en Plotkin, Mariano y Ricardo González Leandri (eds.), Localismo y globalización. Aportes para una historia de los intelectuales en Iberoamérica, Madrid, CSIC, 2000. 
habían sido militantes políticos en diversas agrupaciones de la izquierda radicalizada.

Punto de Vista, sin embargo, recuperó y puso al día algunos elementos importantes del proyecto de Victoria Ocampo. Los editores de la revista se proponían reconstruir el campo intelectual argentino fuertemente dañado por las políticas de la dictadura y recobrar la especificidad de los discursos basada en cierta autonomía del campo de producción intelectual respecto de la política. Los primeros números de Punto de Vista abundan en artículos sobre Sur y sobre Victoria Ocampo. Estos artículos, si leemos entre líneas, tienen un fuerte componente autorreferencial. En general, Sur era un punto de referencia permanente para Punto de Vista, particularmente durante sus primeros años de vida.

La vida de Punto de Vista se ha desarrollado en un contexto (nacional e internacional) totalmente diferente a aquel en el cual se desarrolló Sur. El lugar ocupado por los intelectuales tanto en Argentina como en los Estados Unidos (y se podría decir que también en Europa) había cambiado. Aunque Punto de Vista sigue rescatando la figura del "intelectual" frente a la del "académico", reconoce sin embargo que son estos últimos los nuevos interlocutores relevantes. Al igual que Victoria Ocampo, la gente de Punto de Vista también miraba a algunos elementos de la cultura del Norte (en este caso de la cultura académica del Norte, y el reconocimiento de estos nuevos interlocutores basados en universidades constituye sin duda una innovación importante de Punto de Vista respecto de Sur) en busca de instrumentos interpretativos que le permitieran entender algunos aspectos de la cultura del Sur. En este sentido es significativo que el primer número de Punto de Vista abriera con un artículo escrito por una académica norteamericana (en realidad británica, pero viviendo en los Estados Unidos), Jean Franco, y que este artículo fuera sobre literatura latinoamericana. Como en Sur, la cultura europea continuó ocupando un lugar central en el proyecto de Punto de Vista, pero la revista recapturó y puso al día una visión de la cultura norteamericana que se había originado en Victoria Ocampo y en el aprendizaje que ella había llevado a cabo o que al menos puede ser trazada en sus escritos y que probó ser fructífera en más de un sentido. En algún sentido Victoria Ocampo clausura y al mismo tiempo inaugura una visión sobre los Estados Unidos para la elite intelectual argentina. 